\title{
Calodium hepaticum
}

National Cancer Institute

\section{Source}

National Cancer Institute. Calodium hepaticum. NCI Thesaurus. Code C122256.

A species of parasitic nematodes in the family Capillariidae. C. hepaticum causes hepatic capillariasis in rodents and other mammals. Its life cycle is completed in a single host species but the eggs must mature outside of the host body prior to infecting a new host. 